\title{
Rb-82 generator yield
}

We read with interest the article by Ahmadi et al. ${ }^{1}$ reporting the results of an investigation led by the inventors and developers of RUBY-FILL $\AA$, one of the two marketed ${ }^{82} \mathrm{Sr} /{ }^{82} \mathrm{Rb}$ generators being compared.

We are concerned that the authors incorrectly state that the CardioGen-82 $\AA$ infusion system does not report the integrated total ${ }^{82} \mathrm{Rb}$ activity as part of daily quality control $(\mathrm{QC})$ procedures, but rather the dose calibrator maximum value. They also provide no support for their statement that neither the Patient Dose nor the End-ofInfusion activity values appear to be accurate in the CardioGen-82®daily QC breakthrough elution reports. Moreover, based on the use of a correction factor of 1.314 applied to the dose calibrator maximum values, they suggest that the RUBY-FILL ${ }^{\circledR}$ generator yield is $\sim 7 \%$ higher than that of CardioGen-82®.

The CardioGen-82 ${ }^{\circledR}$ system does provide an integrated dose for each infusion, the Patient Dose, as the authors ultimately acknowledge. For CardioGen-82®, the average difference between the dose calibrator maximum value and the Patient Dose for daily QC is actually a factor of 1.426 , not the 1.314 the authors derived-a difference of $\sim 8 \%$. $^{2}$ Thus, if the true correction factor with the dose calibrator maximum values or the actual integrated calibration doses are used, CardioGen- $82 \AA$ yields are similar to RUBY-FILL ${ }^{\circledR}$ yields.

However, the concept of a yield or elution efficiency is arbitrary when the product has such a short half-life as ${ }^{82} \mathrm{Rb}$, because the 'yield' is dependent on the elution conditions. As the authors note, these are quite different both during daily QC and during normal use for the two systems. What matters is whether the user can get the desired doses over the lifetime of the generator.
In this regard, the maximum dose available is constrained for both generators by the half-life of the ${ }^{82} \mathrm{Sr}$.

Adrian Nunn, PhD, ${ }^{a}$ Peter Oehlberg, $M S^{b}$ ${ }^{a}$ MI-Pharma Consulting, LLC, Lambertville, NJ, USA

${ }^{b}$ Bracco Diagnostics Inc, Monroe Township, NJ, USA

\section{Open Access}

This article is licensed under a Creative Commons Attribution 4.0 International License, which permits use, sharing, adaptation, distribution and reproduction in any medium or format, as long as you give appropriate credit to the original author(s) and the source, provide a link to the Creative Commons licence, and indicate if changes were made. The images or other third party material in this article are included in the article's Creative Commons licence, unless indicated otherwise in a credit line to the material. If material is not included in the article's Creative Commons licence and your intended use is not permitted by statutory regulation or exceeds the permitted use, you will need to obtain permission directly from the copyright holder. To view a copy of this licence, visit http://creativecommons.org/licenses/by/4.0/.

\section{References}

1. Ahmadi A, Klein R, Lewin HC, Beanlands RS, DeKemp RA. Rubidium-82 generator yield and efficiency for PET perfusion imaging: Comparison of two clinical systems. J Nucl Cardiol 2020. https://doi.org/10.1007/s12350-020-02200-6

2. Data on file, Bracco Diagnostics Inc., Monroe Township NJ doi: $10.1007 / \mathrm{s} 12350-020-02287-\mathrm{x}$

Publisher's Note Springer Nature remains neutral with regard to jurisdictional claims in published maps and institutional affiliations. 